\title{
Experiments on Vibration Mitigation with a Mass-Spring-Series Model
}

\author{
Chen-Ming Kuo ${ }^{1}$, Chih-Chiang Lin ${ }^{1 *}$, Yi-Rong Lin ${ }^{2}$ and Cheng-Hao Huang
}

${ }^{1}$ Department of Civil Engineering, National Cheng Kung University, Taiwan

${ }^{2}$ Department of Civil Engineering, National Taiwan University, Taiwan

\begin{abstract}
A mass-spring-series model was assembled and tested using displacement-controlled vibrations in order to validate the effectiveness of vibration mitigation in a floating slab track. A mass mounted with an accelerometer was isolated with a spring from the vibration source. The other end of the mass was also connected with a spring to the fixed end. The spring coefficients and natural frequencies of the mass-spring combinations were carefully measured and verified. The time histories of the vibration amplitude indicated that properly tuned combinations of mass and springs effectively retain vibrations in the designated mass and reduce propagation and reflection. It was determined that using a stiff spring to confront the excitation source and a soft spring as a foundation isolator may alleviate vibration propagation and reduce vibrations reflected to the excitation. The drawbacks of the experimental design were also discussed.
\end{abstract}

Keywords: Coupled model; Rail pad; Railway; Slab bearing; Slab track; Vibration

\section{Nomenclature}

$\mathrm{C}_{b}$ - damping coefficient of slab bearings

$C_{p}$ - damping coefficient of rail fastenings

$C_{v}$ - damping coefficient of suspension

$E_{r}$-Young's modulus of rail

$F_{s f i}$ - the $j$ th slab supporting force

$F_{r s i}$ - the $j$ th fastening force

$h_{w}$ - spacing of the axles in a bogie

$h_{c}$ - spacing between the inner axles of the bogies of the same vehicle

$I_{r}$ - moment of rail inertia

$k$ - spring coefficient

$K_{c}$ - coefficient of contact spring $\left(=8 \times 10^{10} \mathrm{~N} / \mathrm{m}\right)$

$K_{b}$-damping coefficient of slab bearing

$K_{p}$ - spring coefficient of rail fastenings

$K_{v}$-spring coefficient of suspension

$M_{v s}$-mass of a car body

$M_{v u}$-mass of a wheel

$m$ - mass of 4 springs

$m_{r}$-mass of unit length of rail

$M$ - total mass of the steel block, accelerometer, and two steel plates

$N$ - amount of rail fastening

$P_{j}$ - wheel-rail force

$v$ - train speed

$x_{p 1}$ - the distance between the rear wheel and the origin $=x_{p 0}+v t$

$x_{p 2}$ - the distance between the 2 nd rear wheel and the origin $=x_{p 0}$ $+h_{w}+v t$

$x_{p 3}$ - the distance between the 2nd wheel and the origin $=x_{p 0}+\left(h_{w}\right.$ $\left.+h_{c}\right)+v t$

$x_{p 4}$ - the distance between the rear wheel and the origin $=x_{p 0}+\left(2 h_{w}\right.$ $x_{s i}$ - position of the $i$ th rail fastening;

$x_{f}$ - position of the $i$ th slab bearing

$Z_{r}$-vertical deflection of rail

$Z_{v j}$-vertical deflection of the $j$ th carbody

$Z_{w j}$-vertical deflection of the $j$ th wheel

\section{Introduction}

Global warming has made railway transportation increasingly popular because of it is energy efficient and produces relatively few emissions. Railway technology has evolved, resulting in improved mobility and comfort and an attractive, modern, sustainable transportation option. However, expansion of the railway network has also caused environmental concerns. Vibration and noise have major impacts near railway and transit routes. For example, the Taiwan high speed rail passes through the Tainan science-based industrial park (TSIP), one of Taiwan's major wafer fabrication bases, causing leading companies to hesitate to invest in it. The Taipei mass rapid transit system has also faced vibration problems because the Xinzhuang-Luzhou line passes through vibration sensitive areas. Although railway agencies have conducted several research projects on the impact of vibrations on the hi-Tec industrial park, and have adopted a floating slab track, mechanisms employed in vibration mitigation methods require further verification, calibration, and maintenance. A mass-spring-series model was set up to verify the vibration loss associated with various springs. The natural frequency of each mass-spring combination was validated. The idea of trapping vibration in track slabs was tested and discussed. These tests are essential for linking theoretical analysis and practical effectiveness. The experiences that resulted from the tests, as well as the results, are both crucial foundations for future research into railway track vibration mitigation.

*Corresponding author: Chih-Chiang Lin, Department of Civil Engineering National Cheng Kung University, Taiwan, Tel: +886-6-2085608; E-mail: n6897108@mail.ncku.edu.tw

Received September 08, 2016; Accepted October 18, 2016; Published October 20, 2016

Citation: Kuo CM, Lin CC, Lin YR, Huang CH (2016) Experiments on Vibration Mitigation with a Mass-Spring-Series Model. J Civil Environ Eng 6: 253. doi: 10.4172/2165-784X.1000253

Copyright: $\odot 2016$ Kuo CM, et al. This is an open-access article distributed under the terms of the Creative Commons Attribution License, which permits unrestricted use, distribution, and reproduction in any medium, provided the original author and source are credited. 


\section{Review of Railway Vibration Research}

Winkler studied railway structures in 1867 assuming the supporting medium to be independent springs without shear transmission across adjacent springs [1,2]. Hetenyi [3] presented analytical solutions for static loadings on an elastic beam supported by Winkler foundations. Frÿba [4] formulated dynamic models that revealed the dynamic characteristics of moving loads. The models were further improved by introducing moving suspended masses and contact theory, which revealed the coupling effects of various vehicle parameters and speeds [5]. There are many advanced formulations that consider track components in various levels of detail. For example, Hussein and Hunt [6] and Yuan [7] proposed a double-beam system and a complete treatment of the analysis to evaluate interactions between rails and track slabs.

Of the many vibration mitigation techniques, the most fundamental include isolation designs in the track work where the vibrations originate. The isolation design should be tuned to specific frequencies effectively mitigate vibrations. According to basic structural dynamics, the vibration frequencies to be mitigated should be above $\sqrt{2}$ times the natural frequency of the isolation system. However, vibrations with frequencies lower than the threshold might be amplified to some extent. Floating slab track (FST), which basically consists of concrete slabs supported by resilient elements, such as rubber bearings, has been used on modern rail transit systems for years [8]. This design aims to reduce vibrations transmitted to the supporting foundations and surrounding areas. The concept was pioneered on the Washington D.C. rapid transit system (WMATA) in the 1970's. The WMATA's floating slabs are continuous concrete slabs broken only by required construction joints spaced at $18.3 \mathrm{~m}$. Later, in the 1980's, Toronto and Hong Kong's rapid metro systems installed floating tracks consisting of $1.45 \mathrm{~m}$ short slabs. Even shorter slabs were used in the Hong Kong airport express and west railway in the late 1990's. Floating slabs can be continuous if they are cast in-situ, and may be discontinuous if they are constructed in discrete precast sections [9]. Although many studies have reported their effectiveness, the FST remains a controversial method for underground railways because of interactions with the tunnel and the surrounding soil [10]. For example, dynamic loads may occur on wheels passing through gaps between slabs., Significant dynamic force may arise at the wheel-rail interface for heavy axle masses and high-speed trains. Forrest and Hunt [11] studied the effectiveness of floating slab systems and found that isolation is not satisfactory at frequencies as low as predicted by simple theory. Any reductions are modest, and there are some positions around the tunnel at which resilient slab bearings caused increased responses at higher frequencies. Balendra et al. [12] also found that low frequency vibration on floating slab track is more significant than it is on direct fastened track. In addition, experience has shown that the maintenance costs are high and that the quality of the train rides are unsatisfactory [13].

An analytical model for FST can be found in a study of Singapore's rapid transit system [14]. In the meantime, Crockeet and Pyke [15] evaluated the vibration mitigation of floating slab track on viaducts with the finite element package ANSYSs. Recently, Hussein and Hunt [16] derived a three-dimensional model of a deep underground railway tunnel with floating slab track based on the Euler-Bernoulli beam theory. In 2006, Lombaert et al. [17] developed a numerical model to investigate the reduction of free-field vibrations by a floating slab track. They focused on the how dynamic track-soil interaction affected the performance of the floating slab tracks, and concluded that the insertion loss varies with the stiffness of the soil [17]. Although the studies reviewed above shed light on several characteristics from different aspects, in-depth studies that explain the effects of FST on track itself have yet to be completed. Kuo [18] derived and solved a coupled system of floating slab track and wheels with suspended mass to explore the effects of floating slab track on track itself. The study found that the stiffness of slab bearing and slab mass effectively alter rail vibration levels at frequencies above $20 \mathrm{~Hz}$. The authors suggested that a proper combination of stiff rail fastening and soft slab bearings could take care of both environmental vibration and excess rail responses. They presume that the vibration energy might be trapped in the layer of track slabs. Simple mass-spring models have often been used to observe and evaluate insertion losses in isolation systems and to validate design concepts. Jones [19] suggested that soft mats under sleepers may be a useful countermeasure above $20 \mathrm{~Hz}$. Nelson [20] conducted model tests with soft fasteners and achieved 9-12 dB reductions above $30 \mathrm{~Hz}$. A well-designed vibration mitigation method should not only reduce outspreading vibration, but should also prevent the energy from bouncing back to the train. This paper describes laboratory tests done on mass-spring-series models that validate the innovative "stiff rail fastener and soft slab bearing".

\section{Setup of the Mass-Spring-Series Model}

\section{Theoretical background}

The "stiff rail fastener and soft slab bearing" was based on the system shown Figure 1, which was formulated using Eq. (1) to (7). The Eq. were solved and validated to reveal the influence that the stiffness of rail fasteners has on floating slab bearings [18]. The study revealed that FST might cause more severe vibration in rails if the stiffness of the rail fasteners is not tuned properly. The analyses illustrate that stiff rail fasteners accompanied by soft FST bearings significantly reduces vibration amplification in rails, as shown in Figure 2. Consequently,

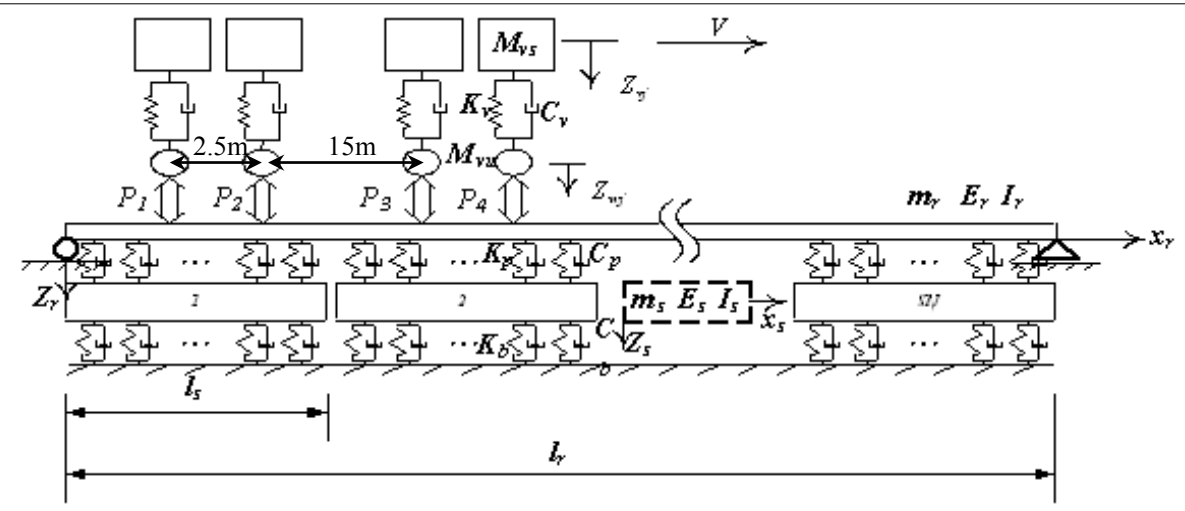

Figure 1: Model of simplified vehicle on floating slab track. 
the vibration energy seems to be trapped in the layer of track slabs. Although further effort is needed to relieve vibration in track slabs, this idea is still useful for track work designs using FST and other vibration mitigations.

Sprung car body,

$$
M_{v s} \ddot{Z}_{v j}(t)+C_{v}\left[\dot{Z}_{v j}(t)-\dot{Z}_{w j}(t)\right]+K_{v}\left[Z_{v j}(t)-Z_{w j}(t)\right]=M_{v s} g
$$

Unsprung wheel,

$$
\begin{aligned}
& M_{v u} \ddot{Z}_{w j}(t)-C_{v}\left[\dot{Z}_{v j}(t)-\dot{Z}_{w j}(t)\right]-K_{v}\left[Z_{v j}(t)-Z_{w j}(t)\right]=M_{v u} g-P_{j}(t) \\
& P_{j}(t)=\left\{\begin{array}{crc}
K_{c}\left[Z_{w j}(t)-Z_{r}\left(x_{p j}, t\right)\right] & \text { if } Z_{w j}(t)-Z_{r}\left(x_{p j}, t\right)>0 \\
0 & \text { if } & Z_{w j}(t)-Z_{r}\left(x_{p j}, t\right) \leq 0
\end{array}\right.
\end{aligned}
$$

Rail,

$$
\begin{aligned}
& E_{r} I_{r} \frac{\partial^{4} Z_{r}(x, t)}{\partial x^{4}}+m_{r} \frac{\partial^{2} Z_{r}(x, t)}{\partial t^{2}}=-\sum_{i=1}^{N} F_{r s i}(t) \delta\left(x-x_{i}\right)+\sum_{j=1}^{4} P_{j}(t) \delta\left(x-x_{p j}\right) \\
& \mathrm{F}_{\mathrm{rsi}}=C_{p}\left[\dot{Z}_{r}\left(x_{s i}, t\right)-\dot{Z}_{s}\left(x_{s i}, t\right)\right]+K_{p}\left[Z_{r}\left(x_{s i}, t\right)-Z_{s}\left(x_{s i}, t\right)\right]
\end{aligned}
$$

Floating slabs,

$$
\begin{aligned}
& E_{s} I_{s} \frac{\partial^{4} Z_{s}(x, t)}{\partial x^{4}}+\frac{M_{s}}{l_{s}} \frac{\partial^{2} Z_{s}(x, t)}{\partial t^{2}}=\sum_{i=1}^{N} F_{r s i}(t) \delta\left(x-x_{s i}\right)-\sum_{i=1}^{N P} F_{s f i}(t) \delta\left(x-x_{f i}\right) \\
& \mathrm{F}_{\mathrm{si}}=C_{b} \dot{Z}_{s}\left(x_{f i}, t\right)+K_{b} Z_{s}\left(x_{f i}, t\right)
\end{aligned}
$$

In order to confirm the idea of "trapping vibration", a mass-springseries model was developed to simulate the track system, as shown in Figure 3. Since the testing machine, an Instron 8800, exerts force through the bottom clamp, the mass-spring series resembles an upside down model of a track structure. The force output of the testing machine can be up to $100 \mathrm{kN}$ force at $2.5 \mathrm{~Hz}$.

\section{Calibration of model parameters}

Different combinations of rail fasteners and slab bearings were assembled with three sets of springs. A spring set composed of four identical springs was welded onto the corners of steel plates. The steel plates were designed for connection with a steel mass or a clamp from the testing machine. The spring coefficient of each set was obtained using an Instron 8800, as shown in Table 1. The calibration equipment is shown in Figure 4. Spring set $\mathrm{A}$ is the stiffest and spring set $\mathrm{C}$ has the lowest spring coefficient.

It is important that the interpretations of the mass-springseries model tests have correct basic natural frequencies. Two steel blocks and three spring sets made up six basic mass-spring sets. The free vibration of each set was measured to compare the natural frequency with the computed frequencies, as shown in Figure 5. The time histories of the vibrations were transformed into a frequency spectrum. As shown in Table 2, the six natural frequencies are fairly
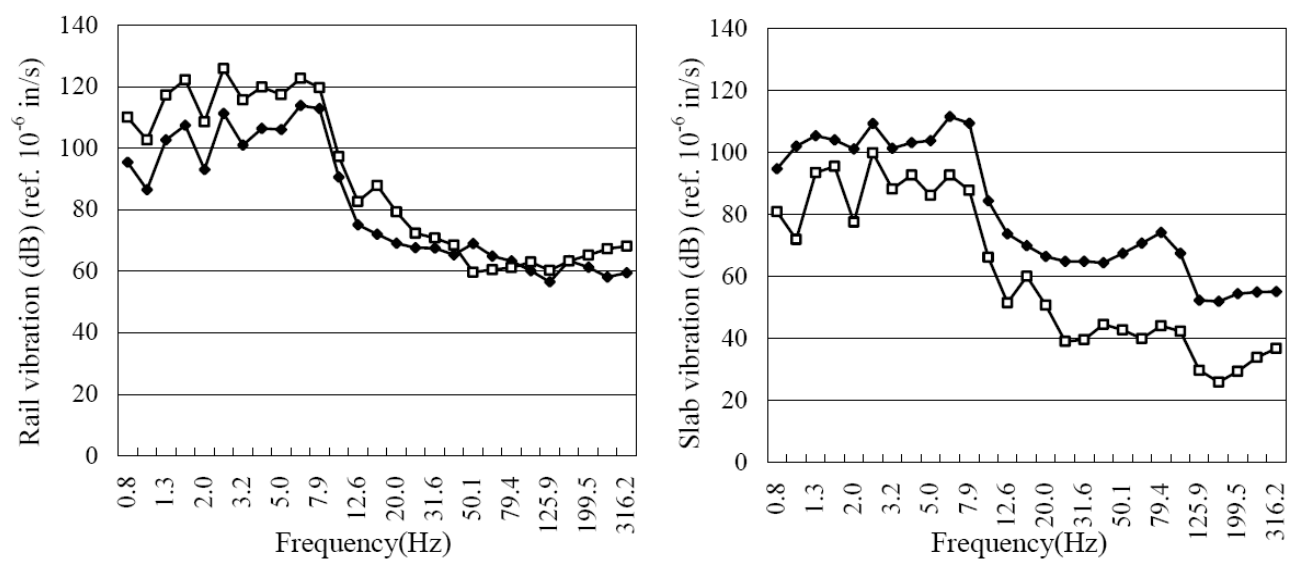

Figure 2: Comparison of the (a) rail vibration spectrum and (b) slab vibration spectrum of two rail fastening stiffness $(k p)$ and slab bearing stiffness $(k b)$, combinations, $k p=182 \mathrm{kN} / \mathrm{mm} k b=5.8 \mathrm{kN} / \mathrm{mm}(\bullet)$, and $k p=13 \mathrm{kN} / \mathrm{mm} \mathrm{kb}=180 \mathrm{kN} / \mathrm{mm}$ ( $\square$ ).

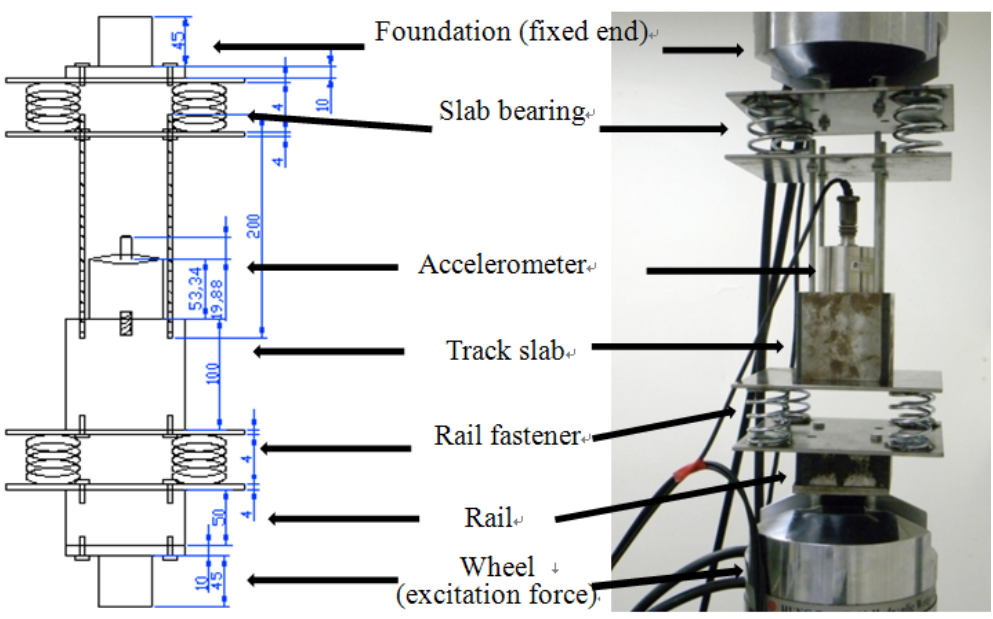

Figure 3: Setup of the mass-spring-series model. 
Citation: Kuo CM, Lin CC, Lin YR, Huang CH (2016) Experiments on Vibration Mitigation with a Mass-Spring-Series Model. J Civil Environ Eng 6: 253. doi: $10.4172 / 2165-784 X .1000253$

Page 4 of 10

close, ranging from $10.4 \mathrm{~Hz}$ to $15.5 \mathrm{~Hz}$. These values are expected to match the natural frequencies calculated with $=\frac{1}{2 \pi} \sqrt{\frac{k}{M}}$, where $\mathrm{k}$ is the spring coefficient and $M$ is the mass of the steel block. However, the mass of vibration is not straightforward because part of the mass of the spring set, including two steel plates and 4 springs, should be added to the steel mass.

As a rule of thumb, the mass of a spring's vibration in a massspring system is one-third of the mass of the spring. The masses of all components in this study are listed in Table 3. Table 4 compares the measured frequencies and the calculated frequencies, including one-third of the mass of a spring set, as shown in Eq. (8). The frequencies matched well for all six cases, with an average error of $0.97 \%$. The mass-spring-series models were assembled by connecting steel mass $\mathrm{A}$, steel mass $\mathrm{B}$, and a clamp, with each

\begin{tabular}{|c|c|c|c|}
\hline Spring set & Test 1 & Test 2 & Average stiffness \\
\hline A & $89.5 \mathrm{~N} / \mathrm{mm}$ & $89.3 \mathrm{~N} / \mathrm{mm}$ & $89.4 \mathrm{~N} / \mathrm{mm}$ \\
\hline B & $57.6 \mathrm{~N} / \mathrm{mm}$ & $57.4 \mathrm{~N} / \mathrm{mm}$ & $57.5 \mathrm{~N} / \mathrm{mm}$ \\
\hline C & $41.8 \mathrm{~N} / \mathrm{mm}$ & $41.2 \mathrm{~N} / \mathrm{mm}$ & $41.5 \mathrm{~N} / \mathrm{mm}$ \\
\hline
\end{tabular}

Table 1: Spring set stiffness test results.

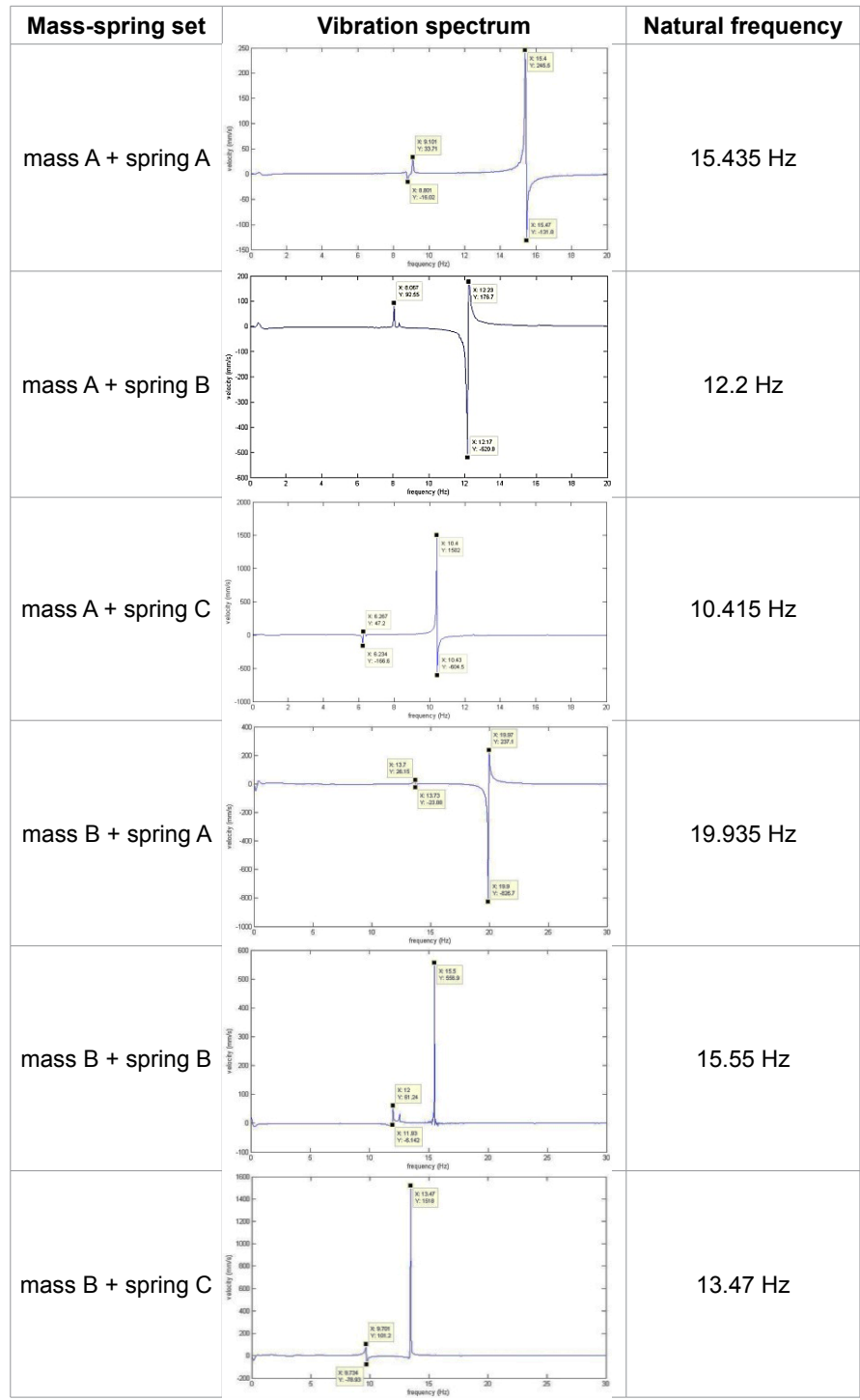

Table 2: Natural frequencies of all mass-spring sets.

\begin{tabular}{|c|c|}
\hline Component & mass $\mathbf{~ g ) ~}$ \\
\hline Steel block A $(100 \mathrm{~mm} \times 100 \mathrm{~mm} \times 100 \mathrm{~mm})$ & 7478 \\
\hline Steel block B $(100 \mathrm{~mm} \times 100 \mathrm{~mm} \times 100 \mathrm{~mm})$ & 3674 \\
\hline 4 Springs in spring set A & 1983.6 \\
\hline 4 Springs in spring set B & 2245.52 \\
\hline 4 Springs in spring set C & 1998.7528 \\
\hline 2 Steel plates in spring set A & 1228.4 \\
\hline 2 Steel plates in spring set B & 1490.48 \\
\hline 2 Steel plates in spring set C & 1343.25 \\
\hline Accelerometer & 500 \\
\hline
\end{tabular}

Table 3: Mass of components in mass-spring models.

\begin{tabular}{|c|c|c|c|}
\hline Models & $\boldsymbol{f}$ (Computed) & $\boldsymbol{f}$ (Measured) & Error \\
\hline Mass A + spring A & $15.47 \mathrm{~Hz}$ & $15.44 \mathrm{~Hz}$ & $0.25 \%$ \\
\hline Mass A + spring B & $12.24 \mathrm{~Hz}$ & $12.20 \mathrm{~Hz}$ & $0.34 \%$ \\
\hline Mass A + spring C & $10.50 \mathrm{~Hz}$ & $10.42 \mathrm{~Hz}$ & $0.79 \%$ \\
\hline Mass B + spring A & $20.01 \mathrm{~Hz}$ & $19.94 \mathrm{~Hz}$ & $0.39 \%$ \\
\hline Mass B + spring B & $15.69 \mathrm{~Hz}$ & $15.55 \mathrm{~Hz}$ & $0.90 \%$ \\
\hline Mass B + spring C & $13.15 \mathrm{~Hz}$ & $13.47 \mathrm{~Hz}$ & $0.50 \%$ \\
\hline
\end{tabular}

Table 4: Verification of natural frequencies.

\begin{tabular}{|l|c|c|}
\hline \multicolumn{1}{|c|}{ Mass-spring-series model } & $\begin{array}{c}\text { Spring } \\
\text { constant }\end{array}$ & $\begin{array}{c}\text { Natural } \\
\text { frequency }\end{array}$ \\
\hline mass A + mass B + spring A + spring B & $146.9 \mathrm{kN} / \mathrm{m}$ & $15.82 \mathrm{~Hz}$ \\
\hline mass A + mass B + spring A + spring C & $130.9 \mathrm{kN} / \mathrm{m}$ & $15.02 \mathrm{~Hz}$ \\
\hline mass A + mass B + spring B + spring C & $99.0 \mathrm{kN} / \mathrm{m}$ & $12.95 \mathrm{~Hz}$ \\
\hline
\end{tabular}

Table 5: Computed natural frequencies of mass-spring-series models.

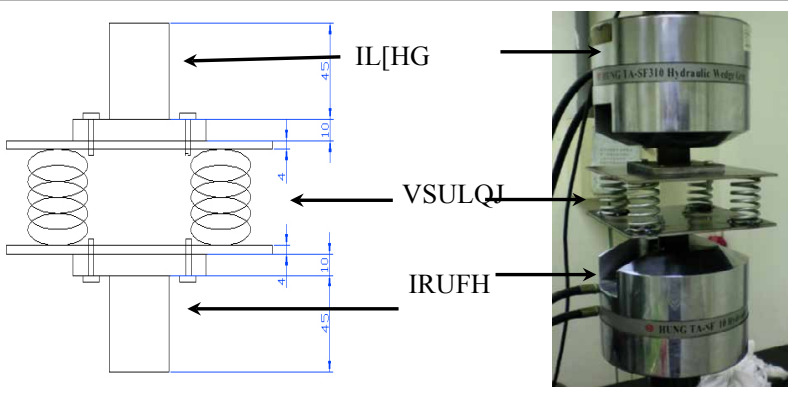

Figure 4: Spring calibration.

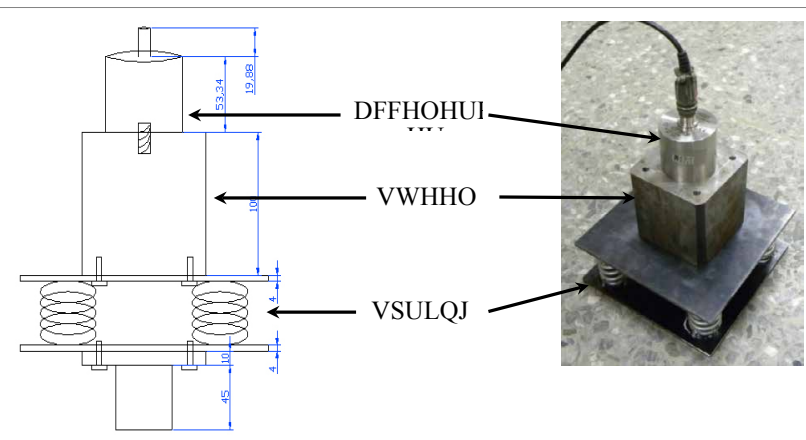

Figure 5: Natural frequency measurement.

spring sets. The characteristic frequencies of the series models were calculated as shown in Table 5 .

$$
\mathrm{f}=\frac{1}{2 \pi} \sqrt{\frac{k}{\mathrm{M}+1 / 3 \mathrm{~m}}}
$$


Citation: Kuo CM, Lin CC, Lin YR, Huang CH (2016) Experiments on Vibration Mitigation with a Mass-Spring-Series Model. J Civil Environ Eng 6: 253. doi: $10.4172 / 2165-784 X .1000253$

Page 5 of 10

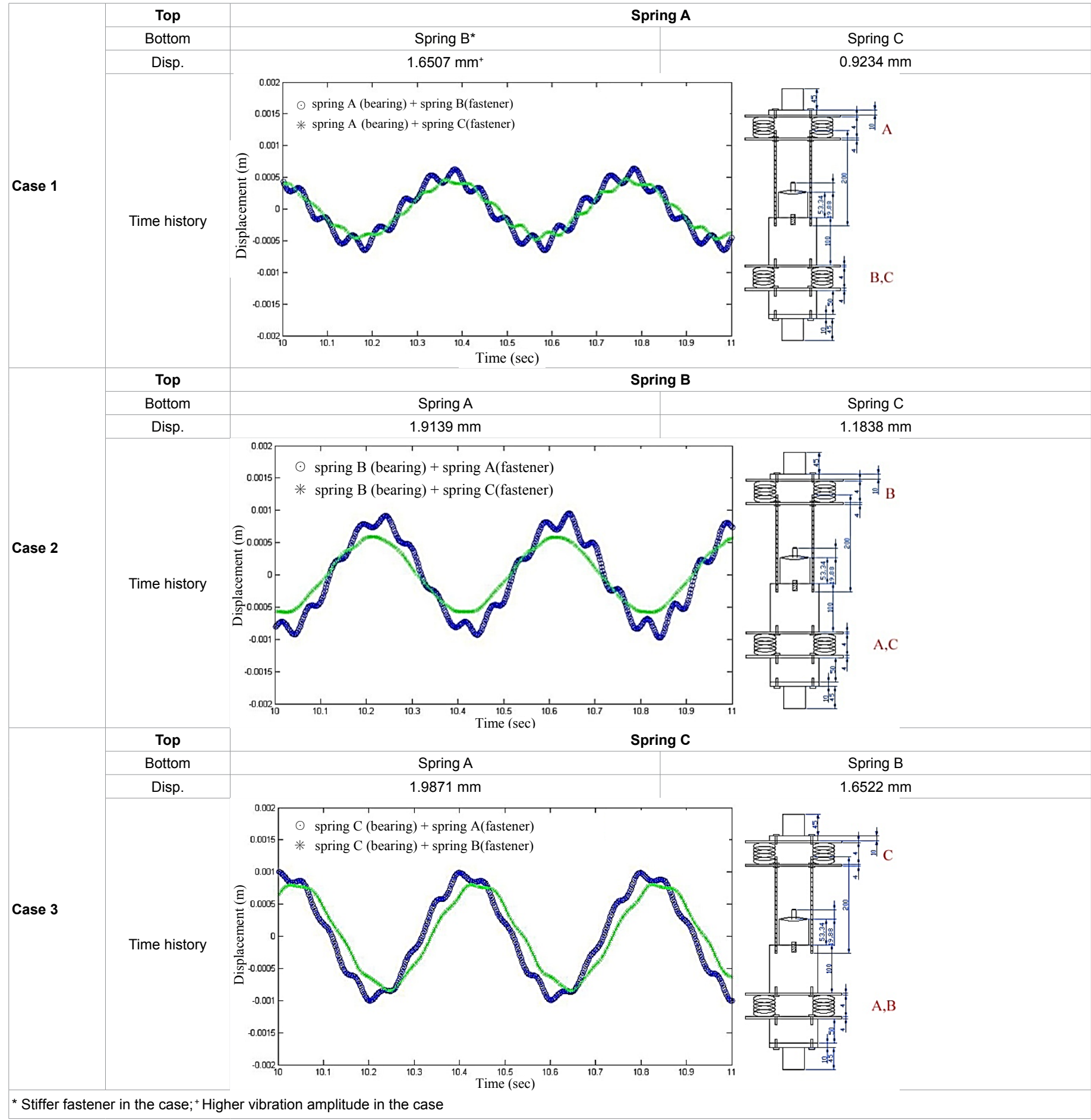

Table 6: Effectiveness of a rail fastener on vibration amplitude.

\section{Time History of Track Slab Displacement}

By changing the top spring and bottom spring in Figure 3, six models were tested by applying a $2.5 \mathrm{~Hz}$ sinusoidal force with $1 \mathrm{~mm}$ amplitude. The results were interpreted in two ways. First, the effectiveness of the rail fastener on the vibration of the track slabs was examined, as shown in Table 6. All comparisons demonstrated that a stiffer bottom spring (resembling a rail fastener) results in significantly larger vibration amplitude. That is, wheel-rail impact induced vibrations are more likely to pass through stiff rail fasteners and cause larger displacement in track slabs. The other methods of comparison focused on slab bearings. Table 7 illustrates that a stiffer top spring (resembling a slab bearing) results in smaller vibration amplitude in the mass (resembling a track slab). In other words, although soft bearings may isolate vibrations from propagation to foundation, they tend to retain vibration energy in the track itself. Both comparisons qualitatively validate an effect that suggests that a soft spring may keep vibration energy on the side of the excitation and reduce displacement on the received side. Based on this concept, track slabs on the receiving side of rail fasteners experience more severe vibrations when they are underneath softer rail 
Citation: Kuo CM, Lin CC, Lin YR, Huang CH (2016) Experiments on Vibration Mitigation with a Mass-Spring-Series Model. J Civil Environ Eng 6: 253. doi: $10.4172 / 2165-784 X .1000253$

Page 6 of 10

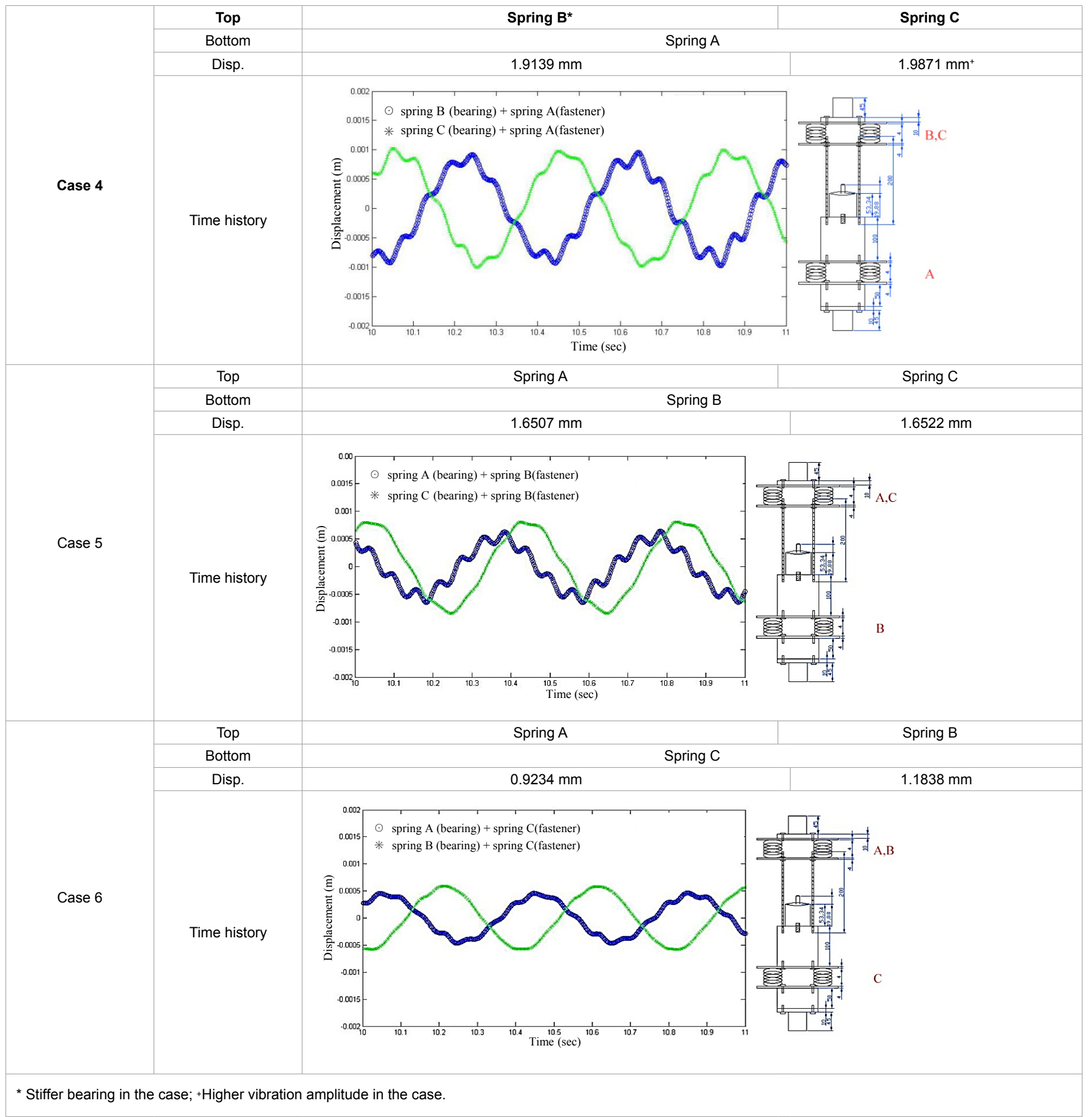

Table 7: Effectiveness of slab bearing on vibration amplitude.

fasteners. On the other hand, the track slab is source of excitation for slab bearings and subgrades. It is reasonable to expect to observe more severe displacement of track slabs on softer bearings.

\section{Frequency Spectrum of Track Slab Velocity}

The time histories of the vibration velocities for the six tests were transformed into frequency domain in order to study the effectiveness of different frequency ranges for vibration mitigation. The spectrums of the vibration level were averaged and presented at the central frequencies of a one-third octave band. As shown in Tables 8 and 9 , two peak frequencies were apparent, $2.5 \mathrm{~Hz}$ and $16 \mathrm{~Hz}$, in all tests. The cause of the low frequency peak, $2.5 \mathrm{~Hz}$, is straightforward. It matches the testing machine excitation frequency, which is $2.5 \mathrm{~Hz}$. The $16 \mathrm{~Hz}$ vibration peak resulted from the natural frequency of the mass-springseries model. As listed in Table 5, the natural frequency may be 12.95 $\mathrm{Hz}, 15.02 \mathrm{~Hz}$, or $15.82 \mathrm{~Hz}$ depending on the spring set in the model. In order to interpret the vibration mitigation effects of rail fasteners from a frequency point of view, spectrums were compared, as shown 
Citation: Kuo CM, Lin CC, Lin YR, Huang CH (2016) Experiments on Vibration Mitigation with a Mass-Spring-Series Model. J Civil Environ Eng 6: 253. doi: 10.4172/2165-784X.1000253

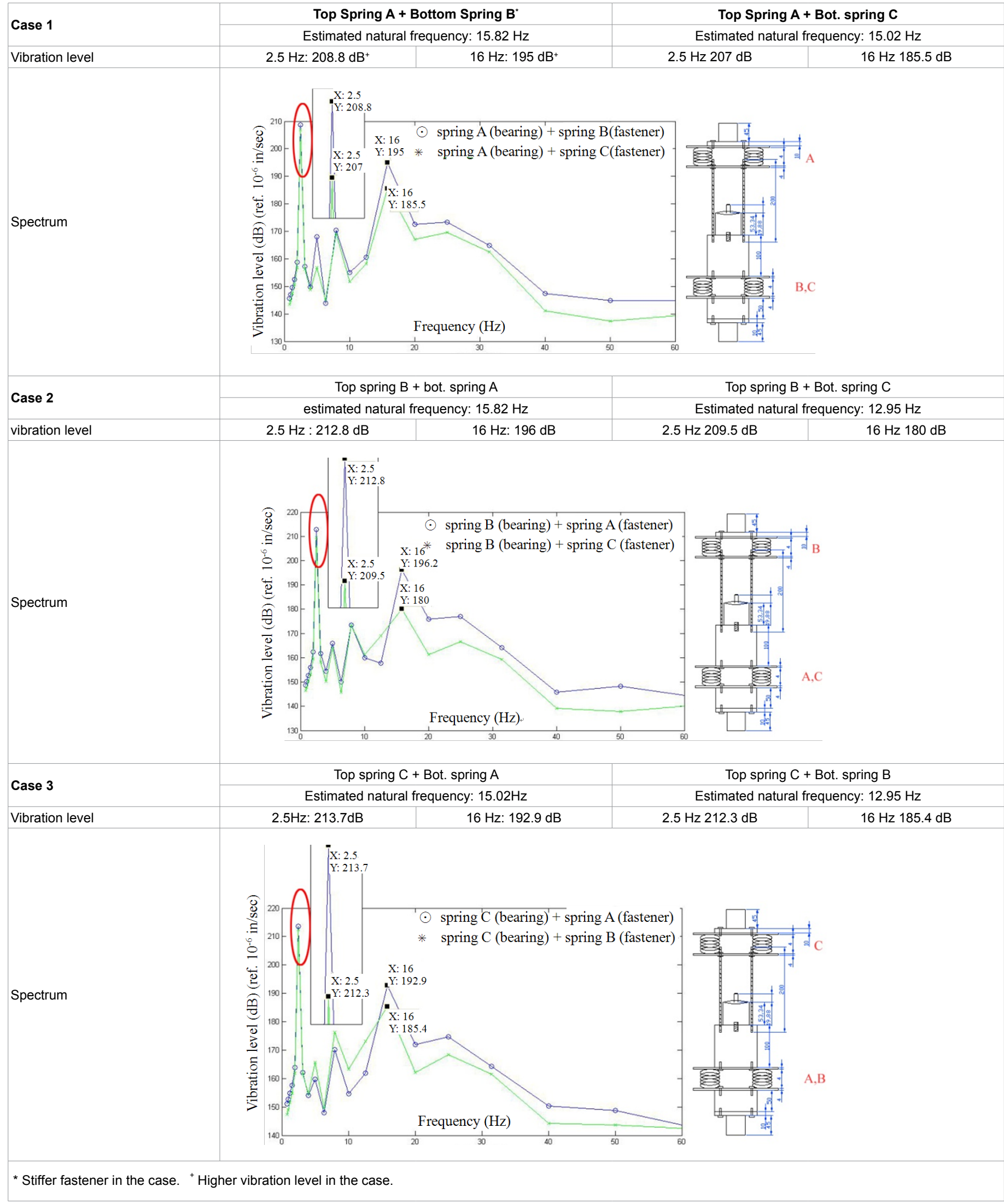

Table 8: Spectral analysis of effectiveness of rail fastener 
Citation: Kuo CM, Lin CC, Lin YR, Huang CH (2016) Experiments on Vibration Mitigation with a Mass-Spring-Series Model. J Civil Environ Eng 6: 253. doi: 10.4172/2165-784X.1000253

Page 8 of 10

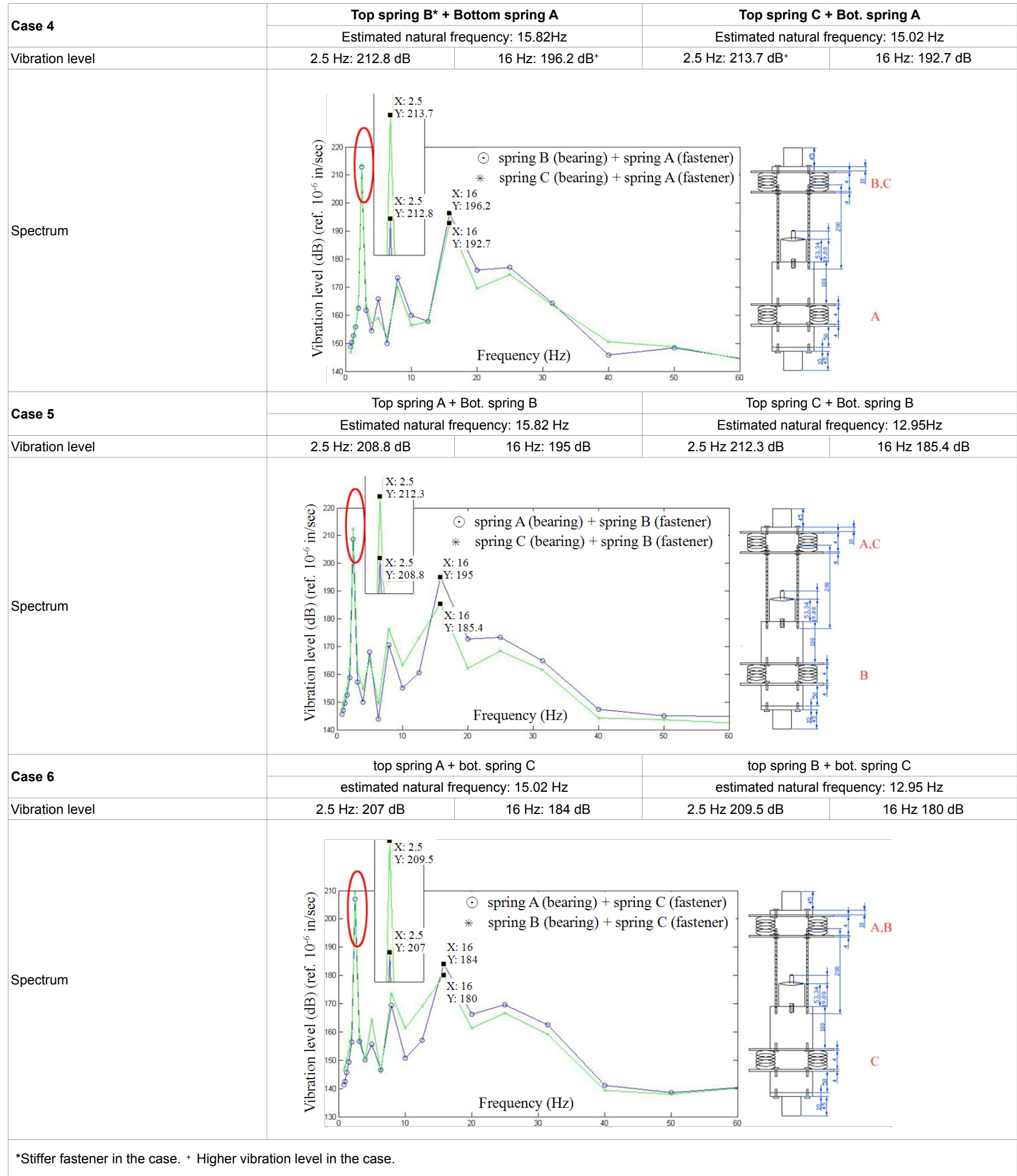

Table 9: Spectral analysis of effectiveness of slab bearing 


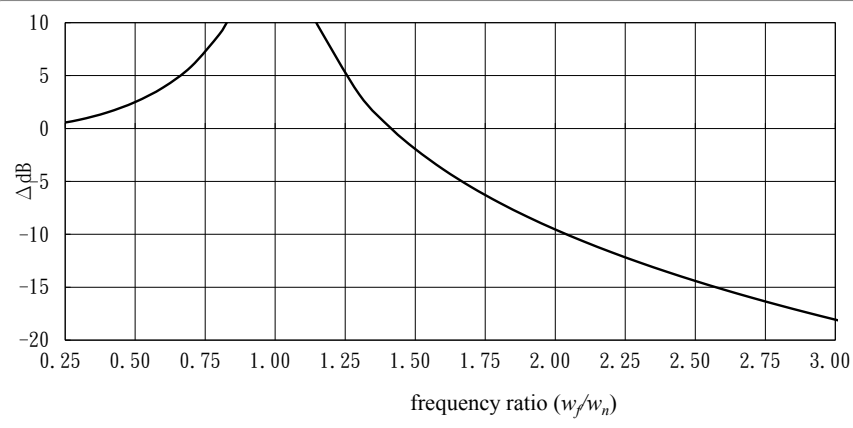

Figure 6: Frequency response curve.

in Table 8. A high vibration level appeared in the model with a stiff bottom spring for both peak frequencies. The soft bottom spring was effective for retaining vibration in mass A (track slab), especially at the $16 \mathrm{~Hz}$ vibration. This phenomenon can be attributed to the fact that the effective frequency range of vibration mitigation is generally located above $\sqrt{2}$ times the natural frequency of the isolation system. In this study, mass $\mathrm{B}$, on the bottom clamp and the connecting spring, are considered the bottom isolation system. The characteristic frequency was $19.95 \mathrm{~Hz}$ for spring set $\mathrm{A}, 15.55 \mathrm{~Hz}$ for spring set $\mathrm{B}$, and $13.47 \mathrm{~Hz}$ for spring set $\mathrm{C}$. Consequently, the isolation system should be effective for excitations above $18 \mathrm{~Hz}$. This should explain why mitigations for $2.5 \mathrm{~Hz}$ are minor, but those for $16 \mathrm{~Hz}$ are noticeable. Table 9 further examines the vibration mitigation effects of slab bearings from a frequency point of view. It is interesting to note that the model with the high vibration level at $16 \mathrm{~Hz}$ was not consistent with the one that had high vibration at $2.5 \mathrm{~Hz}$. That is to say, although the $2.5 \mathrm{~Hz}$ vibrations were impeded by a soft top spring and the high vibration level in mass A (track slab), the vibration level at $16 \mathrm{~Hz}$ was lower than that of the counterpart model. Further inspection indicated that the natural frequency of mass A on spring B was $12.2 \mathrm{~Hz}$, and that the natural frequency of mass A on spring $\mathrm{C}$ was $10.5 \mathrm{~Hz}$. Even though the $2.5 \mathrm{~Hz}$ vibration tended to be enlarged in both models according to the frequency response curve (Figure 6), the model with spring $\mathrm{C}$ magnified $2.5 \mathrm{~Hz}$ vibration more than the model with spring $\mathrm{B}$. On the other hand, $16 \mathrm{~Hz}$ vibrations are located in the reduction region of the figure. The model with spring $\mathrm{C}$ and a $10.5 \mathrm{~Hz}$ natural frequency reduced $16 \mathrm{~Hz}$ vibration more than the model with spring B on top. Despite the complicated phenomena in the frequency spectrum due to experimental design flaws, the initiative proposed in this study was successfully validated for the dominant excitation of $2.5 \mathrm{~Hz}$ vibration.

\section{Conclusions}

A mass-spring-series model was set up to validate "trapping" vibrations in track slabs to avoid reflecting the vibrations back to rails and propagating vibrations to the foundation. Spring coefficients were measured and the basic natural frequencies were calibrated through tests and theoretical calculations. The major findings are as follows:

The vibration amplitude of the model with the stiff bottom spring was found higher than that of the model with the soft bottom spring. This concurs with the idea that vibration is prone to transmit through a stiff pad. In railway practice, appropriate stiffness of rail fasteners should be evaluated to allow vibration to pass through them instead of being reflected back to the rails. The model with a soft top spring resulted in higher amplitude than that of the model with a stiff top spring. This again concurs with the idea that vibration tends to be bounced back by a soft pad. This justifies the design concept of floating slab tracks for vibration mitigation along railway routes.
Spectral analyses of vibration velocity revealed two peak frequencies. The $2.5 \mathrm{~Hz}$ came from the exertion force of the testing machine. The $16 \mathrm{~Hz}$ vibrations arose from the natural frequencies of the model. The initiative of trapping vibration in track slabs with a stiff rail fastener and soft slab bearings was successfully validated from both vibration displacement and from the velocity spectrum. The experimental design in this study has two major drawbacks. First, the frequency of exertion force should be above $20 \mathrm{~Hz}$ to be in an effective range of vibration mitigation for the models. However, $20 \mathrm{~Hz}$ has exceeded the capacity of the testing machine available in the department of civil engineering, National Cheng Kung University. The other drawback is that the mass and springs were not carefully tuned to separate natural frequencies and coincidently caused resonance, which interfered with data interpretation.

\section{Acknowledgements}

This work was supported by the Taiwan National Science Council under Grant NSC 98-2815-C-006-065-E.

\section{References}

1. Coenraad E (2001) Modern railway track (2ndedn). The Netherland, MRTProduction.

2. Wu JS, Shih PY (2000) The dynamic behaviour of a finite railway under the high-speed multiple moving forces by using finite element method. John Wiley \& Sons, Ltd, 851-866.

3. Hetenyi M (1946) Beams on elastic foundation, ann arbor, michigan: University of Michigan press.

4. Frÿba L (1972) Vibrations of solids and structures under moving loads Noordhoff International Publishing, Groningen, The Netherlands.

5. Knothe K, Grassie SL (1993) Modelling of railway track and vehicle/track interaction at high frequencies. Veh Syst Dyn 22: 53.

6. Hussein MFM, Hunt HEM (2003) An insertion loss model for evaluating the performance of floating-slab track for underground railway tunnels. in 10th international congress on sound and vibration, ICSV1, Stockholm, Sweden. 419-426.

7. Yuan J, Zhu Y, Wu M (2009) Vibration characteristics and effectiveness of floating slab track system. J Computers 12: 1249-1254.

8. Wilson GP, Saurenman HJ, Nelson JT (1983) Control of ground-borne noise and vibration. J Sound Vib 87: 339-350.

9. Mohammed H (2004) Dynamic effect of slab discontinuity on underground moving trains. in Proceedings of the Eleventh International Congress on Sound and Vibration, St. Petersburg, Russia.

10. Talbot JP (2000) Reduction of train-induced vibration in buildings. in Engineering Transactions, Polish Academy of Sciences. Institute of Fundamental Technological Research.

11. Forrest JA, Hunt HEM (2006) A three-dimensional tunnel model for calculation of train-induced ground vibration. J Sound Vib 294: 678-705.

12. Balendra T, Chua KH, Lo KW, Lee SL (1989) Steady-state vibration of subwaysoil-building system. J Eng Mech ASCE 115: 145-162.

13. Connor P (2004) Modern Railway Glossary.

14. Cui F, Chew CH (2000) The effectiveness of floating slab track system: Part I. Receptance methods. Appl Acoust 61: 441-453.

15. Crockett AR, Pyke JR (2000) Viaduct Design for minimization of direct and structure-radiated train noise. J Sound Vib 231: 883-897.

16. Hussein MFM, Hunt HEM (2006) Modelling of floating-slab tracks with continuous slabs under oscillating moving loads. J Sound Vib 297: 37-57.

17. Lombaert G, Degrande G, Kogut J, François S (2006) The experimental validation of a numerical model for the prediction of railway induced vibrations. J Sound Vib 297: 512-535.

18. Kuo CM, Huang CH, Chen YY (2008) Vibration characteristics of floating slab track. J Sound Vib 317: 1017-1034. 
Citation: Kuo CM, Lin CC, Lin YR, Huang CH (2016) Experiments on Vibration Mitigation with a Mass-Spring-Series Model. J Civil Environ Eng 6: 253. doi: $10.4172 / 2165-784 X .1000253$

Page 10 of 10

19. Jones CJC (1994) Use of numerical models to determine the effectiveness of anti-vibration systems for railways. $p$ of the institute of civil engineers. Transportation 105: 43-51.
20. Nelson JT (1996) Recent Developments In Ground-Borne Noise And Vibration Control. J Sound Vib 193: 367-376. 